\title{
DRUG UTILIZATION STUDY ON ANTIBIOTICS USE IN AN ORTHOPAEDICS DEPARTMENT OF A TERTIARY CARE HOSPITAL IN WEST BENGAL
}

\author{
*Ghosh Amit Kumar ${ }^{1}$, Dalai Chanchal Kumar ${ }^{2}$, Kumar Ajay $^{3}$ and. Ray Madhumita ${ }^{4}$ \\ ${ }^{1}$ Associate Professor, Department of Pharmacology, R.G.Kar Medical College \& Hospital, Kolkata \\ ${ }^{2}$ Assistant Professor, Department Of Pharmacology, College of Medicine and JNM Hospital, Kalyani, Nadia \\ ${ }^{3}$ Assistant Professor, Department of Orthopaedics, College of Medicine and JNM Hospital, Kalyani, Nadia \\ ${ }^{4}$ Final Year PGT (Anaesthesiology), Department of Anaesthesiology, Calcutta National Medical College \& Hospital, Kolkata \\ *Corresponding author's Email: chanchal.dalai8@ gmail.com, Mobile No.09474550728
}

\begin{abstract}
Background: antibiotics are the commonly prescribed in the Orthopaedics Department both as prophylactically (before orthopaedics surgery etc) or to treat ongoing infection (like septic arthritis, osteomyelitis ${ }^{11}$ etc). But if antibiotics are not use rationally then there will be increase chances of resistance of bacteria as also as increase the total cost of treatment. This study was conducted to see the antibiotics utilization pattern.

Aim: This drug utilization study was conducted to evaluate the pattern of antibiotics use in Orthopaedic Unit of a tertiary care, teaching hospital in west Bengal, India.

Settings and Design: A cross-sectional, unicentric drug utilization study

Results: A total of 410 prescriptions were studied; in which 136 prescriptions contained mono-antibiotic therapy (35.17\%) and 274 prescriptions contained poly-antibiotics therapy $(66.83 \%)$ and the beta-lactum antibiotics were most commonly prescribed (42.3\%).

Conclusion: Beta-Lactum antibiotics were most commonly prescribed and poly-antibiotics prescriptions were the common pattern.

Key words: Drug Utilization Study, antibiotics, unicentric study
\end{abstract}

\section{INTRODUCTION}

The World Health Organization (WHO) addressed drug utilization as the marketing, distribution, prescription and use of drugs in a society, considering its consequences, either medical, social, and economic. ${ }^{1}$ Studies on the process of drug utilization focus on the factors related to the prescribing, dispensing, administering, and taking of medication, and its associated events, covering the medical and non-medical determinants of drug utilization, the effects of drug utilization, as well as studies of how drug utilization relates to the effects of drug use, beneficial or adverse. ${ }^{2,3}{ }^{4}$ The therapeutic practice is expected to be primarily based on evidence provided by pre marketing clinical trials, but complementary data from post marketing period are needed to provide an adequate basis for improving drug therapy. ${ }^{5}$

Antibiotics being the most commonly prescribed group of drugs, the problem of it's over use is a global phenomenon. In India the prevalence of use of antimicrobial agents varies from 24 to $67 \%$. ${ }^{6}$ As per kunin's criteria it was observed that $64 \%$ of total antibiotics prescribed were either not indicated or inappropriate in terms of drug or dosage and was estimated that in India, they account for over $50 \%$ of the value of drugs sold. ${ }^{7}$ In several situations, the rational use of antibiotics has been reported to have reduced the emergence of resistant strains. The prescribing behavior of physician depends upon the input from various sources like patients, commercial publicity, professional colleagues, academic literature and government regulations. ${ }^{8}$ Ineffective use of these inputs can result in a wide variety of prescribing errors.
Antibiotics are commonly prescribed medicine in Orthopaedics Unit. ${ }^{9}$ The antibiotics are prescribed both as prophylactically ${ }^{10}$ (before orthopaedics surgery etc) or to treat ongoing infection (septic arthritis, osteomyelitis ${ }^{11}$ etc). Infection is a very important problem in the orthopaedic surgery because of its continuing incidence, clinical importance and serious sequelae, the treatment being very difficult and expensive (for example, the treatment of an infected hip prosthesis costs twice as much as an aseptic revision and six times as much as the primary replacement).Rates of infection have been reduced by antibiotic prophylaxis, but the increasing number of implants used means that there are still many patients affected each year. Implants are avascular and therefore antibiotics can reach them only by diffusion from the surrounding tissues. Infection involving an implant cannot be cured simply with antibiotics and it often necessitates the surgical removal of the implant. ${ }^{12}$

This drug utilization study was conducted to study antibiotics use in an Orthopaedics Department of a tertiary care, teaching hospital.

\section{MATERIALS AND METHODS}

\section{SUBJECT SELECTION CRITERIA}

The subjects who had willingly participated were enrolled on the basis of inclusion and exclusion criteria. All the patients using antibiotics, between 18-60 years of age, irrespective of sex, were studies. However, patients who were pregnant, lactating, unable to comply due to mental 
retardation, unconsciousness or drug addiction were excluded from the study.

\section{STUDY SETTING}

This study was carried out in the Orthopaedic Unit of College of Medicine \& JNM Hospital, Kalyani, Nadia,West Bengal, India.

STUDY DESIGN: Cross sectional and unicentric drug utilization study.

\section{DURATION OF STUDY}

The duration of study was six months (July 2012 to December 2012).

\section{STUDY POPULATION}

The present study was conducted on 410 patients who visited the Orthopaedics Unit during the 6-month period.

\section{PARAMETERS FOR EVALUATION}

the parameters included gender distribution, age of the patients, type of infection, type of antimicrobial prescribed, prescribed in generic form, average number of drugs per prescription.

\section{STUDY METHODOLOGY}

A cross-sectional, unicentric study was conducted in the Orthopaedic Department (both indoor \& outdoor) of an urban, tertiary care, Medical College \& Hospital in west Bengal during July 2012 to December 2012. Prescriptions were collected from patients attending the Orthopaedic Department. The prescription patterns of antibiotics agents were analyzed. No follow up of prescription was done.

\section{RESULT AND ANALYSIS}

In a six months period from July 2012 to December 2012, a total of 410 patients were included in the study and their prescriptions containing at least one antibiotic were analyzed only once time- no follow up visit was done.

The demographic profile has been described in TABLE 1, FIGURE 1, and 2.

TABLE 1: DEMOGRAPHIC CHARACTERISTICS

\begin{tabular}{|c|c|c|}
\hline PATIENT CHARACTERISTICS & $\begin{array}{c}\text { NUMBER OF } \\
\text { PRESCRIPTION }\end{array}$ & PERCENTAGE (\%) \\
\hline \multicolumn{3}{|l|}{ AGE IN YEARS } \\
\hline $18-30$ & 157 & 38.29 \\
\hline $31-40$ & 55 & 13.41 \\
\hline $41-50$ & 76 & 18.53 \\
\hline $51-60$ & 122 & 29.75 \\
\hline MALE & 220 & 53.65 \\
\hline FEMALE & 190 & 46.55 \\
\hline \multicolumn{3}{|l|}{ MALE:FEMALE RATIO $1.15: 1$} \\
\hline \multicolumn{3}{|l|}{ DIAGNOSIS } \\
\hline RTA(Road Traffic Accident) & 215 & 52.43 \\
\hline Post Operative & 146 & 35.6 \\
\hline Chronic osteomyliis & 36 & 08.78 \\
\hline Septic Arthritis & 21 & 05.12 \\
\hline Acute osteomylitis & 12 & 02.92 \\
\hline PRESCRIBING INDICATORS: & ugs /prescrit & 4 \\
\hline
\end{tabular}

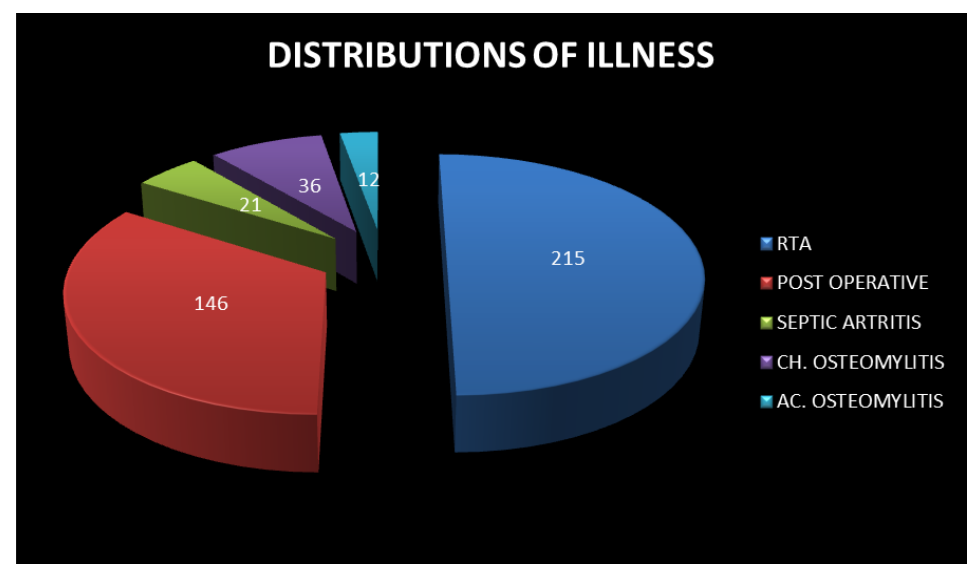

Figure 1: shows sex wise distribution 


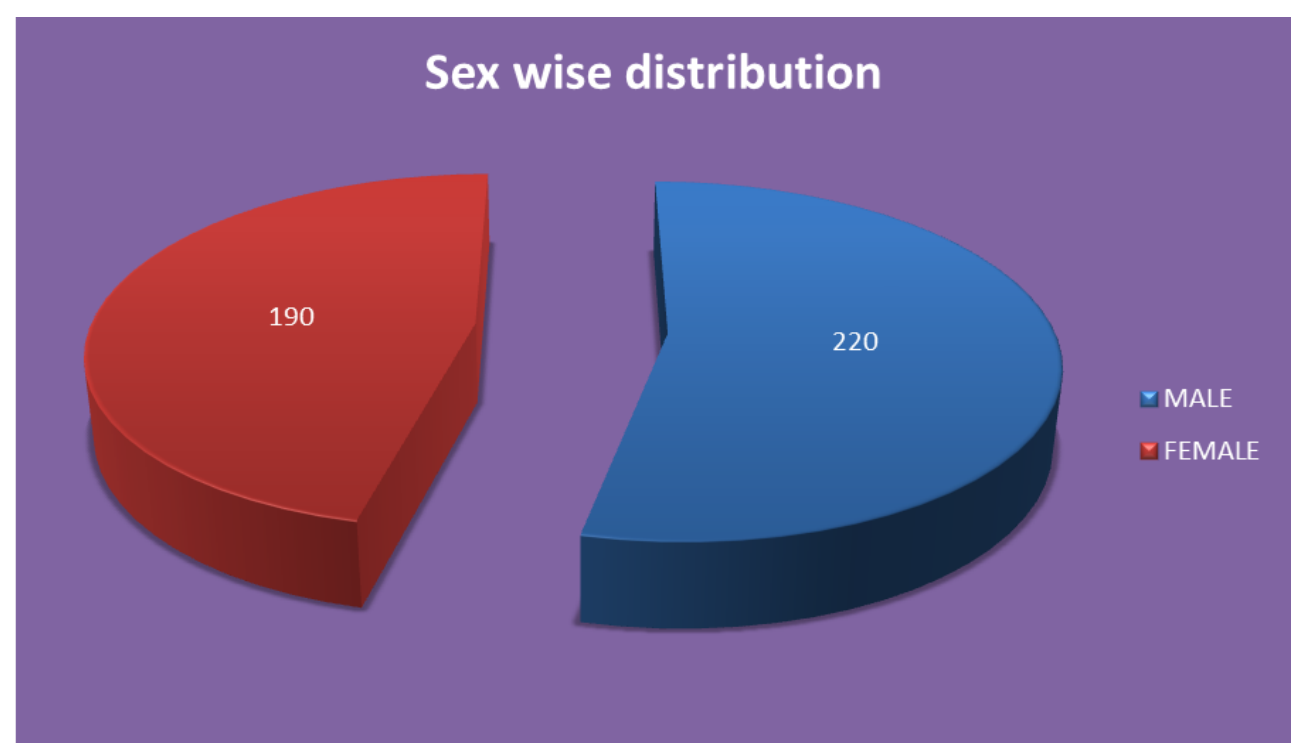

Figure 2: Distributions of illness

Groupwise distribution of antibiotics

The antibiotics are tabulated group wise in table 2 and figure 3 .

Table 2: Groupwise distribution of antibiotics

\begin{tabular}{|c|c|c|c|c|}
\hline GROUPS & NAME OF ANTIBIOTICS & NUMBER & TOTAL NUMBER & PERCENTAGE (\%) \\
\hline \multirow[t]{5}{*}{ BETA LACTUM } & CEFTRIAXONE & 130 & \multirow{5}{*}{305} & \multirow{5}{*}{42.3} \\
\hline & CEFOPERAZONE & 29 & & \\
\hline & CEFUROXIME & 110 & & \\
\hline & CEFIXIME & 22 & & \\
\hline & AMPICILLIN & 14 & & \\
\hline \multirow[t]{2}{*}{ FLUOROQUINOLONES } & CIPROFLOXACIN & 92 & \multirow[b]{2}{*}{105} & \multirow[b]{2}{*}{14.56} \\
\hline & OFLOXACIN & 13 & & \\
\hline \multirow[t]{3}{*}{ OTHERS } & $\begin{array}{l}\text { AMIKACIN } \\
\text { (AMINOGLYCOSIDES) }\end{array}$ & 88 & 88 & 12.2 \\
\hline & METRONIDAZOLE & 155 & 155 & 21.49 \\
\hline & LINEZOLID & 68 & 68 & 09.43 \\
\hline
\end{tabular}

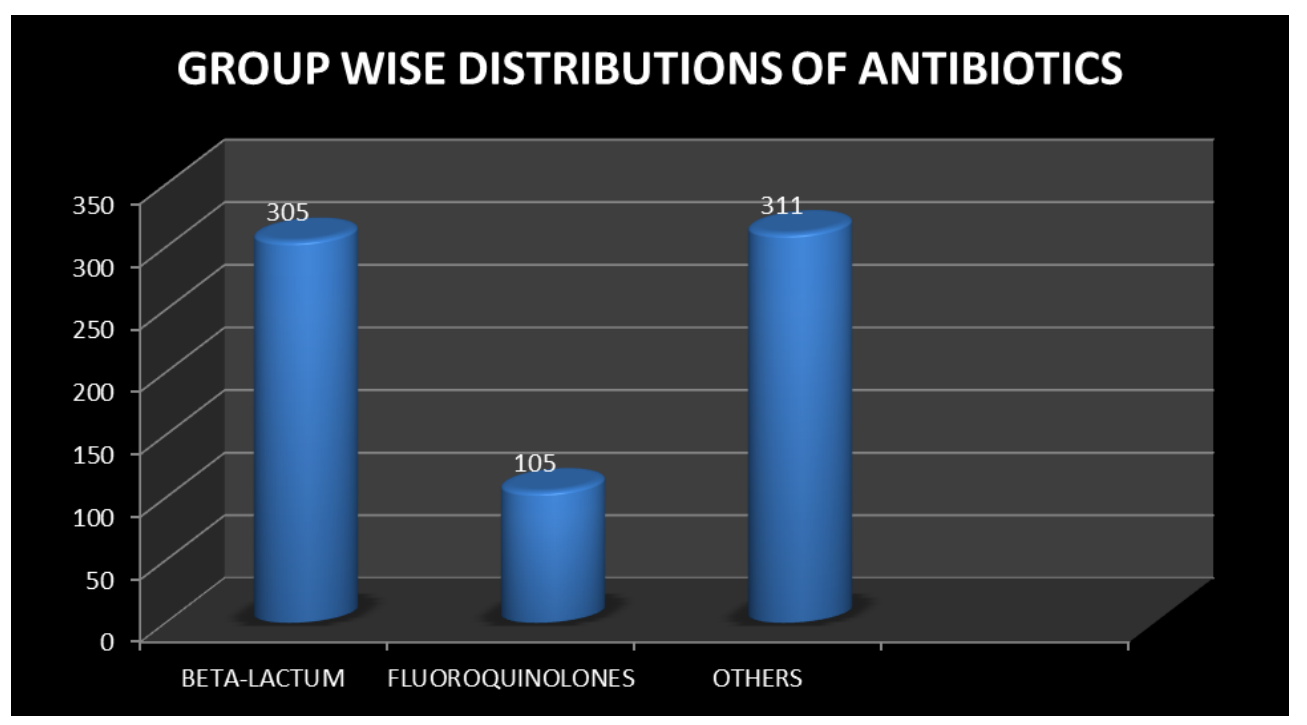

Figure 3: Shows the Distributions of Antibiotics 


\section{MONO -ANTIBIOTIC THERAPY}

Among the total of 410 prescriptions, there were 136 prescriptions contained single antibiotic (33.17\%). The details of seven antibiotics prescribed in single are tabulated in Table 3 and Figure 4.

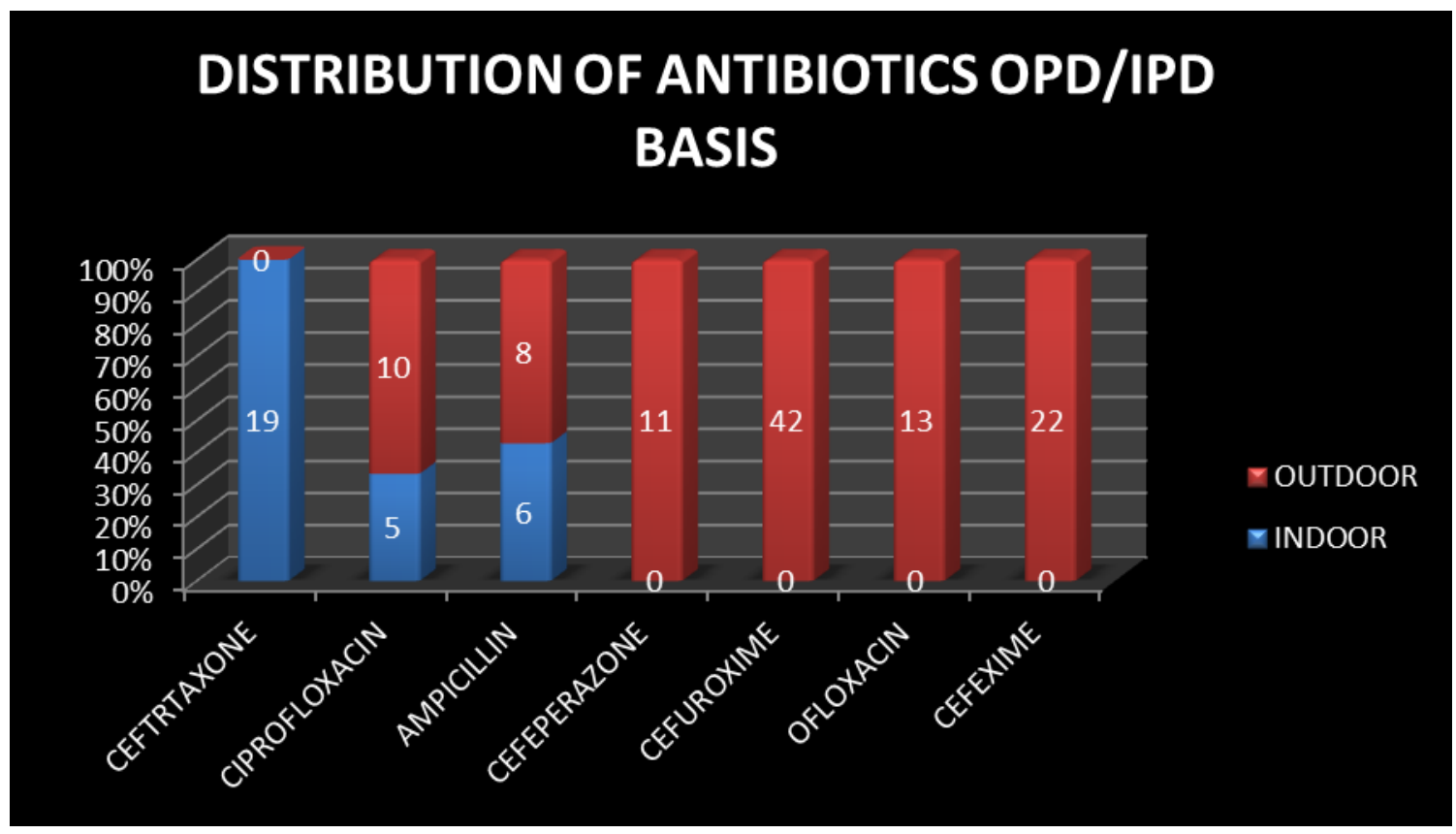

Figure 4: shows the indoor/outdoor basis distribution

Table 3: Antibiotics prescribed in single (Mono-Antibiotic Therapy)

\begin{tabular}{|l|c|c|c|}
\hline $\begin{array}{l}\text { NAME OF THE COMBINATION } \\
\text { WITH DOSE \& ROUTE OF ADMINISTRATION }\end{array}$ & Indoor & Outdoor & Total Prescription \\
\hline [Infusion Metronidazole 400mg T.D.S.+ inj. Ceftriaxone 1gm BD] I.V. & 78 & & 78 \\
\hline [Inj. Ceftrixone 1gm+ Inj. Amikacin 500mg] I.V. BD & 33 & & 33 \\
\hline Inj. Cefoperazone 1gm+ Inj. Amikacin 500mg I.V. BD & 18 & & 18 \\
\hline $\begin{array}{l}\text { [Inj. Ciprofloxacin 500 mg +Ing. Amikacin 500mg] I.V. BD + Infusion } \\
\text { Metronidazole 400mg TDS IV }\end{array}$ & 37 & & 37 \\
\hline [Cefuroxime 500 mg+Linezolid 600 mg] BD Oral & 18 & 50 & 68 \\
\hline [Ciprofloxacine 500 BD+Metrogyl400 TDS] Oral & 12 & 28 & 40 \\
\hline
\end{tabular}

Table 4: Details of the Antibiotics Combination (Poly-Antibiotic Therapy)

\begin{tabular}{|c|c|c|c|}
\hline $\begin{array}{c}\text { NAME OF THE } \\
\text { ANTIBIOTICS }\end{array}$ & PRES. IN INDOOR & PRES. IN OUTDOOR & TOTAL PRESCRIPTION \\
\hline CEFTRIAXONE & 19 & 00 & 19 \\
\hline CIPROFLOXACIN & 05 & 10 & 15 \\
\hline AMPICILLIN & 06 & 08 & 11 \\
\hline CEFOPERAZONE & 00 & 42 & 42 \\
\hline CEFUROXIME & 00 & 13 & 13 \\
\hline OFLOXACIN & 00 & 22 & 22 \\
\hline
\end{tabular}




\section{POLY- ANTIBIOTICS THERAPY}

Among the total of 410 prescriptions, there were 274 prescriptions contained poly antibiotics $(66.83 \%)$.The details of six type of combination of antibiotics are tabulated in Table 4.

\section{ANTIBIOTICS PRESCRIBED IN GENERIC FORM}

Antibiotics prescribed in generic form are tabulated in details in table no.5 and figure 5.

Table 5: antibiotics prescribed in generic form

\begin{tabular}{|l|c|c|c|}
\hline NAME OF DRUGS & $\begin{array}{l}\text { NUMBER OF } \\
\text { PRESCRIPTIONS }\end{array}$ & $\begin{array}{l}\text { PRESCRIPTIONS IN } \\
\text { GENERIC FORM }\end{array}$ & PERCENTAGE (\%) \\
\hline CIPROFLOXACIN & 92 & 77 & 83.69 \\
\hline CEFTRIAXONE & 130 & 108 & 83.07 \\
\hline CEFOPERAZONE & 29 & 00 & 00 \\
\hline CEFUROXIME & 110 & 00 & 00 \\
\hline CIFIXIME & 22 & 00 & 00 \\
\hline METRONIDAZOLE & 155 & 141 & 100 \\
\hline AMPICILLIN & 14 & 14 & 70.45 \\
\hline AMIKACIN & 88 & 62 & 00 \\
\hline OFLOXACIN & 13 & 00 & 00 \\
\hline LINEZOLID & 68 & 00 & \\
\hline
\end{tabular}

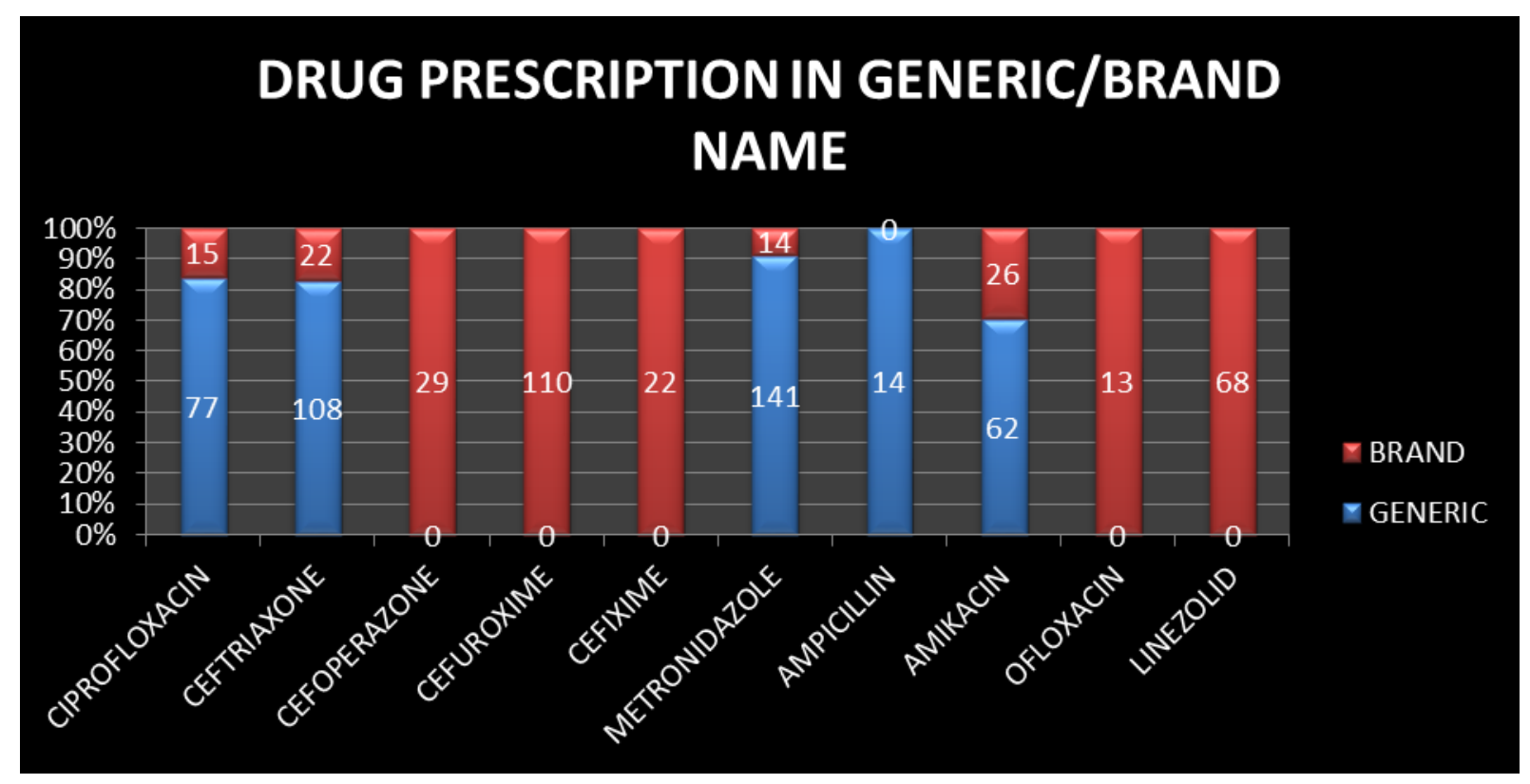

Figure 5: Shows the Generic/Brand Prescription of Different Antibiotics

\section{ADVERSE EVENTS}

Adverse events of antibiotics as asked by the patients or doctors are tabulated in TABLE NO 6.

Table 6: adverse events

\begin{tabular}{|l|l|l|l|c|l|}
\hline $\begin{array}{l}\text { Name of the } \\
\text { antibiotics }\end{array}$ & Route & Dose & $\begin{array}{l}\text { Symptoms } \\
\text { (within 24 hrs) }\end{array}$ & $\begin{array}{l}\text { Number of } \\
\text { cases }\end{array}$ & Fate \\
\hline Metronidazole & ORAL, I.V. & $400 \mathrm{mg}$ T.D.S & Nausea, vomiting & 60 & Continue the medicine \\
\hline Ceftriaxone & I.V. & $1 \mathrm{gm}$ B.D. & Rash, itching & 03 & Stop the medicine \\
\cline { 4 - 6 } & & & Hypersensitivity reaction & 02 & \\
\hline Ampicilline & I.V. & $500 \mathrm{mg}$ TDS & Rash, itching & 02 & \multirow{2}{*}{ Stop the medicine } \\
\cline { 3 - 5 } & & & Shock, Hypersensitivity & 05 & \multirow{2}{*}{ Stop the medicine } \\
\hline Cefoperazone & I.V. & 1 gm B.D. & hypersensitivity & 02 & Stop the medicine \\
\hline Linezolid & Oral & $600 \mathrm{mg}$ B.D. & Itching, rash & 04 & \\
\hline
\end{tabular}




\section{DISCUSSION}

In general practice, the therapeutic approach for orthopaedic infection is primarily empirical and the main aim of the physicians is to treat as specifically as possible. The present study indicates the general trends of use of antibiotics in both indoor patient department (IPD) and outdoor patient department (OPD) of Orthopaedics Department.

Demographic characteristics showed that percentage of males suffering from infection was more than females (male: female- 1.15:1).Further it was noted that a majority of the patients were age group of 18-30 years (38.29\%) and the lowest percentages were in 31-40 years (13.41\%).

Road Traffic Accident (RTA) was the most common clinical situation where antibiotics were prescribed in high percentage $(52.43 \%)$ where acute osteomylitis was the least $(02.92 \%)$.

Most commonly prescribed category of antibiotics was found to be beta-lactum (42.3\%) followed by metronidazole $(14.56 \%)$.Ceftriaxone was the most common antibiotic among beta-lactum group.

When prescriptions were screened thoroughly, the number of prescriptions of mono-antibiotic prescription (single antibiotic/prescription) were $136 \quad(33.17 \%)$ where prescriptions containing poly-antibiotic therapy were 274 $(66.83 \%)$.This presentation represent that poly-antibiotic

\section{REFERENCE}

1. WHO Expert Commitee. The Selection of Essential Drugs,technical Report Series no.615, Geneva: World Health Organization, 1977.

2. Lunde PK, Baksaas I. Epidemiology of drug utilization basic concepts and methodology, Acta Med Scand Suppl, 1988; 721:7-11.

3. Strom BL. Pharmacoepidemiology. Fourth ed: John Wiley\& Sons, Ltd. 2005

4. Costa J, Rosa MM, Ferreira JJ, Sampaio C, Vaz Carneiro A. [Cardiac effects of acute poisoning with tricyclic antidepressants: systematic review of the literature. Part I], Rev Port Cardiol, 2001; 20:671-8.

5. Strom BL, Melmon KL, Miettinen OS. Postmarketing studies of drug efficacy, Arch Intern Med, 1985; 145:1791-4.

6. Kulshrestha S., Aggrawal K.K. Survey of pattern of antimicrobial use in teaching hospital, Ind J. Pharmacol, 1984; 16(1): 395 . prescription were more preferred than mono-antibiotic therapy.

Among the mono-antibiotic therapy, cefuroxime was prescribed most commonly (42 prescription) and cefoperazone was the least (11 prescription).

In poly-antibiotic therapy, [Infusion Metronidazole 400mg T.D.S. + inj. Ceftriaxone 1gm BD] I.V. combination was prescribed mostly (78\%).

Some antibiotics were prescribed generically (like ciprofloxacine, ceftriaxone, metronidazole, ampicillin and amikacin) in more frequently [table no 5]; the cause may be due to its free availability in hospital pharmacy. The antibiotics which were not supplied in the hospital pharmacy were not prescribed generically.

The adverse events like rash, itching, hypersensitivity were commonly seen in beta-lactum group of antibiotics.

\section{CONCLUSION}

In Orthopaedic Department, antibiotics were commonly prescribed in poly-antibiotics form to treat the infection. Beta-Lactum group was the commonly prescribed antibiotics in July 2012-December 2012.

7. Kunin C.M. Rational use of antibiotics, WHO Drug Information, 1990; 4(1): 4-7.

8. Wilkowske C.J. General principles of antimicrobial therapy, Mayo Clin Proc, 1991; 66: 931-41.

9. M I Yusof, A H Yusof. Orthopaedic Infections: Organisms and Antibiotic Sensitivity, Med J Malaysia, 2004; 59(5):574-7.

10. Norden CW. Antibiotic prophylaxis in orthopedic surgery, Clin Orthop Relat Res, 1976; 114:203-6.

11. Luca Lazzarini, Benjamin A. Lipsky, Jon T. Mader. Antibiotic treatment of osteomyelitis: what have we learned from 30 years of clinical trials? International Journal of Infectious Diseases,2005; 9:127-138.

12. Purghel F, Badea R, Ciuvica R, Anastasiu A . The use of antibiotics in traumatology and orthopaedic surgery.Mædica - a Journal of Clinical Medicine, 2006; 1(3):58-65. 